OPEN ACCESS

Edited by:

Marcus M. Seldin,

University of California, Irvine,

United States

Reviewed by:

Fernando Rodriguez-Pascual, Consejo Superior de Investigaciones

Cientificas (CSIC), Spain

Philip C. Trackman,

Boston University, United States

*Correspondence:

Junxia Yan

20457456@qq.com

${ }^{\dagger}$ These authors have contributed equally to this work

Specialty section:

This article was submitted to

Systems Endocrinology,

a section of the journal

Frontiers in Endocrinology

Received: 18 December 2020 Accepted: 29 June 2021 Published: 28 July 2021

Citation:

Luo C, Hu C, Li B, Liu J, Hu L,

Dong $R$, Liao $X$, Zhou J, Xu L,

Liu S, Li Y, Yuan D, Jiang $W$ and

Yan J (2021) Polymorphisms in

Lysyl Oxidase Family Genes Are

Associated With Intracranial Aneurysm Susceptibility in a Chinese Population.

Front. Endocrinol. 12:642698.

doi: 10.3389/fendo.2021.642698

\section{Polymorphisms in Lysyl Oxidase Family Genes Are Associated With Intracranial Aneurysm Susceptibility in a Chinese Population}

\author{
Chun Luo ${ }^{1+}$, Chongyu $\mathrm{Hu}^{2+}$, Bingyang $\mathrm{Li}^{1,3}$, Junyu Liu ${ }^{4}$, Liming Hu${ }^{1}$, Rui Dong ${ }^{1}$, \\ Xin Liao ${ }^{1,5}$, Jilin Zhou ${ }^{4}, \mathrm{Lu} \mathrm{Xu}^{4}$, Songlin Liu ${ }^{4}$, Yifeng $\mathrm{Li}^{4}$, Dun Yuan ${ }^{4}$, Weixi Jiang ${ }^{4}$ \\ and Junxia Yan ${ }^{1,6 *}$
}

${ }^{1}$ Department of Epidemiology and Health Statistics, XiangYa School of Public Health, Central South University, Changsha, China, ${ }^{2}$ Department of Neurology, Hunan People's Hospital, Changsha, China, ${ }^{3}$ Department of Information Statistics, Changsha Hospital of Traditional Chinese Medicine (Changsha Eight Hospital), Changsha, China, ${ }^{4}$ Department of Neurosurgery, XiangYa Hospital, Central South University, Changsha, China, ${ }^{5}$ Department of Scientific Research, The People's Hospital of Guangxi Zhuang Autonomous Region, Nanning, China, ${ }^{6}$ Hunan Provincial Key Laboratory of Clinical Epidemiology, XiangYa School of Public Health, Central South University, Changsha, China

Purpose: Intracranial aneurysms (IA) comprise a multifactorial disease with unclear physiological mechanisms. The lysyl oxidase (LOX) family genes (LOX, LOX-like 1-4) plays important roles in extracellular matrix (ECM) reconstruction and has been investigated in terms of susceptibility to IA in a few populations. We aimed to determine whether polymorphisms in LOX family genes are associated with susceptibility to IA in a Chinese population.

Methods: This case-control study included 384 patients with IA and 384 healthy individuals without IA (controls). We genotyped 27 single nucleotide polymorphisms (SNPs) of LOX family genes using the Sequenom MassARRAY ${ }^{\circledR}$ platform. These SNPs were adjusted for known risk factors and then, odds ratios (OR) and 95\% confidence intervals $(\mathrm{Cl})$ were evaluated using binary logistic regression analysis.

Results: The result showed that LOX rs10519694 was associated with the risk of IA in recessive (OR, 3.88; 95\% Cl, 1.12-13.47) and additive (OR, 1.56; 95\%Cl, 1.05-2.34) models. Stratified analyses illustrated that LOX rs10519694 was associated with the risk of single IA in the recessive $(\mathrm{OR}, 3.95 ; 95 \% \mathrm{Cl}, 1.04-15.11)$ and additive $(\mathrm{OR}, 1.64 ; 95 \%$ $\mathrm{Cl}, 1.04-2.56)$ models. The LOXL2 rs1010156 polymorphism was associated with multiple IA in the dominant model $(\mathrm{OR}, 1.92 ; 95 \% \mathrm{Cl}, 1.02-3.62)$. No associations were observed between SNPS of LOXL1, LOXL3, and LOXL4 and risk of IA.

Conclusion: $L O X$ and $L O X L 2$ polymorphisms were associated with risk of single IA and multiple IA in a Chinese population, suggesting potential roles of these genes in IA. The effects of these genes on IA require further investigation.

Keywords: intracranial aneurysm, lysyl oxidase family genes, LOX gene, LOXL2, polymorphism 


\section{INTRODUCTION}

Intracranial aneurysms (IA) are cystic bulges caused by local defects or increased pressure in the intracranial artery wall (1). Unruptured intracranial aneurysms (UIA) occur in $3-5 \%$ of the global population and in 7\% of Chinese persons aged 35-75 years $(2-5)$. The annual risk of IA rupture is $0.5-1.8 \%(6,7)$. The rupture of an IA can result in aneurysmal subarachnoid hemorrhage (aSAH), which can be fatal in $50 \%$ of patients and cause $33 \%$ of severe sequelae $(8,9)$. Costs associated with aSAH supervision exceed $£ 510$ million annually in the UK (10). Therefore, risk factors linked to IA should be determined as soon as possible to screen and treat IA more effectively.

In addition to the established acquired risk factors of cigarette smoking and hypertension, genetic factors also play significant roles in IA (3). Among patients with IA, $4 \%$ and $8 \%$ have firstand second-degree relatives with IA, respectively (11). The predicted probability of IA is higher among individuals with hereditary pathologies such as autosomal dominant polycystic kidney disease (ADPKD) and Marfan syndrome (12). The extracellular matrix (ECM) is an indispensable element for maintaining arterial wall stability. A disrupted balance between ECM synthesis and degradation may be the pathophysiological basis for IA formation $(13,14)$. For example, some single nucleotide polymorphisms (SNPs) of endothelin receptor type A (EDNRA), alpha 1 type III collagen (COL3A1), transcription factor SOX-17 (SOX17), and lysyl oxidase-like 2 (LOXL2), which are mainly involved in ECM reconstruction, are associated with IA (15-18). The LOXL2 gene belongs to the lysyl oxidase (LOX) family that comprises $L O X$ and lysyl oxidase-like 1-4 (LOXL1, LOXL2, LOXL3, and LOXL4) (19). Lysyl oxidase can initiate covalent crosslinking between soluble collagen and elastin monomers that are converted into insoluble, stable fibers in the ECM, thereby ensuring the structural and functional stability of the arterial wall (20). Dysregulated LOX activity may play significant roles in cardiovascular diseases such as atherosclerosis and aneurysms (21), which are mediated by cross-linked structural ECM proteins. Thus, the LOX family of genes might be associated with IA.

So far, few population studies have explored associations between polymorphisms in LOX family genes and IA, and the results were inconsistent. For instance, associations between $L O X$ gene polymorphisms and IA have not been found in Japanese, Central European, and South Indian populations (22-24). However, a recent population study in Korea found three SNPs of LOX (rs2303656, rs3900446, and rs763497) were significantly associated with IA (maximum OR, 20.15; $P=4.8 \times 10^{-5}$ ) (25). Akagawa et al. (18) examined associations between LOXL1-4 gene polymorphisms and susceptibility to familial intracranial aneurysms (FIA) in Japan and found that rs1010156 of LOXL2 was associated with FIA (OR, 1.49; $\mathrm{P}=0.023)$. Using whole exome sequencing (WES), Wu et al. (26) also discovered that the rare variant of LOXL2, c.133C > T (rs142252012), is related to the FIA susceptibility in a Chinese population. Considering genetic heterogeneity among ethnic populations and that the genetic background of FIA might differ from that of sporadic intracranial aneurysms (SIA), we aimed to determine whether polymorphisms in LOX family genes are associated with susceptibility to IA in a Chinese population.

\section{METHODS}

\section{Study Population}

We recruited 384 consecutive patients with IA at Xiangya Hospital of Central South University and the Hunan Provincial People's Hospital (Chang Sha, Hunan province, China) since January 2016. The diagnosis and phenotype information of IA (number, location, and rupture status) was confirmed by magnetic resonance imaging (MRI), computed tomography (CTA), or digital subtraction (DSA) angiography. Other neurological and vascular conditions such as arteriovenous malformation and Marfan syndrome were excluded. We also randomly selected 384 healthy individuals (control), who visited a district community health service center for routine annual health check-up and had no personal or family history of IA, $\mathrm{SAH}$, or other known related vascular diseases. Demographic information and clinical data were collected using a questionnaire and from medical records. None of the participants were consanguineous. Peripheral venous blood sample was collected from all participants into $5 \mathrm{~mL}$ EDTAK2 anticoagulant tubes (Sanli Medical Technology Co., Ltd., Liuyang, China). All participants provided written, informed consent before the study was initiated. The study was performed under the approval of the Ethics Committee at Central South University (Permit No: CTXY-150002-1). Furthermore, to test the robust of the association results identified in this study, an additional population control was adopted (208 normal Chinese Han individuals in the 1000 Genomes Project, the genotype information was download from http://grch37.ensembl.org/ Homo_sapiens/Info/Index).

\section{SNP Selection and Genotyping}

We selected SNPs based on tag SNP and determined by Genome Variation Server 150 (http://gvs.gs.washington.edu/GVS150/ index.jsp). The threshold of the LD parameter $\mathrm{r}^{2}$ was set at 0.8 . The minor allele frequency (MAF) of all selected SNPs was $>5 \%$. After tag SNP screening by gene name, priority was given to variants with a proven relationship to IA or SNPs located in the functional exonic region or that covered many other sites. We finally selected 27 SNPs of $L O X$ family genes into this study (Table 1). Among them, LOX rs2303656, rs763497, and rs3900446 SNPs were positively related to IA in a Korean population (25), while LOXL2 rs1010156 and rs142252012 SNPs were positive in Japanese and Chinese families, respectively $(18,26)$.

Genomic DNA was extracted using TIANamp Blood Genomic DNA Isolation kits (TIANGEN Biotech Co., Ltd., Beijing, China) and stored at $-80^{\circ} \mathrm{C}$. Primers were designed according to the SNP loci using Assign Design 3.1 software (http://agenacx.com) and their sequences are detailed in Table 1. Target SNPs were genotyped using the MassARRAY iPlex platform (Agena Bioscience Inc., San Diego, CA, USA). 
TABLE 1 | Information of LOX family genes polymorphisms.

\begin{tabular}{|c|c|c|c|c|c|c|c|c|c|c|}
\hline \multirow{2}{*}{$\begin{array}{l}\text { Gene } \\
\text { (Genbank } \\
\text { accession } \\
\text { number) }\end{array}$} & \multirow[t]{2}{*}{ SNPs } & \multirow[t]{2}{*}{ Position } & \multirow[t]{2}{*}{ Role } & \multicolumn{2}{|c|}{ Variant } & \multirow[t]{2}{*}{ MAF $^{d}$} & \multirow{2}{*}{$\begin{array}{l}\text { Forward primer sequence } \\
\qquad\left(5^{\prime}-3^{\prime}\right)\end{array}$} & \multirow{2}{*}{$\begin{array}{l}\text { Reverse primer sequence } \\
\qquad\left(5^{\prime}-3^{\prime}\right)\end{array}$} & \multirow{2}{*}{$\begin{array}{l}\text { Length } \\
\text { (bp) }\end{array}$} & \multirow[t]{2}{*}{ SNPs covered by tag SNPs } \\
\hline & & & & cDNA & $\begin{array}{l}\text { Amino } \\
\text { Acid }\end{array}$ & & & & & \\
\hline \multirow{6}{*}{$\begin{array}{l}\text { LOX } \\
\text { (NM_002317) }\end{array}$} & $\begin{array}{l}\text { rs } 1800449 \\
(C>T)^{a}\end{array}$ & Chr5:122077513 & Missense & c. $473 \mathrm{C}>\mathrm{T}$ & p.R158L & 0.17 & AGAAGTTCCTGCGCTCAGTA & TGGGCCTTTCATAAGTATCG & 134 & rs2288393/rs10059661 \\
\hline & $\begin{array}{l}r s 2956540 \\
(G>C)^{a}\end{array}$ & Chr5:122073485 & Intron & $\begin{array}{l}\text { c. } 1035 \\
+528 \mathrm{G}>\mathrm{C}\end{array}$ & - & 0.21 & TTCACCTGTGAAACCATTCC & GAAATGGTGTCCTTCTGCTC & 152 & - \\
\hline & $\begin{array}{l}\text { rs } 10519694 \\
(C>T)^{a}\end{array}$ & Chr5:122071524 & Intron & $\begin{array}{l}\text { c.346- } \\
935 \mathrm{C}>\mathrm{T}\end{array}$ & - & 0.05 & ATGCCACATCACTCCACTTG & CTGAGGAAACTTCTCTAGAC & 135 & - \\
\hline & $\begin{array}{l}r s 2303656 \\
(G>T)^{b}\end{array}$ & Chr5:122070281 & Intron & $\begin{array}{l}\text { c.1132- } \\
113 G>T\end{array}$ & - & 0.02 & CTGGGCAACACAAAGAGTTC & TाTCCATAACGTCTCCAGAG & 141 & - \\
\hline & $\begin{array}{l}\text { rs763497 } \\
(A>G)^{b}\end{array}$ & Chr5:122091535 & Intergenic & - & - & 0.13 & ACATCTAGGCCTACATCGAG & TAAATGGCCCCCAACACAAG & 129 & - \\
\hline & $\begin{array}{l}r s 3900446 \\
(A>G)^{b}\end{array}$ & Chr5:122090980 & Intergenic & - & - & 0.12 & AGGAAGCAAAGCTCAGGTGG & CTTGAAGTTCCCAGTAAGG & 120 & - \\
\hline \multirow{4}{*}{$\begin{array}{l}\text { LOXL1 } \\
\text { (NM_005576) }\end{array}$} & $\begin{array}{l}r s 2165241 \\
(C>T)^{a}\end{array}$ & Chr15:73929861 & Intron & $\begin{array}{l}\text { c. } 1102 \\
+1976 C>T\end{array}$ & - & 0.07 & АAACTGAGCTCTCAAATGCC & СТСТСААТСААСТGGСТTCC & 131 & $\begin{array}{c}\text { rs750460/rs4243042/ rs4886782/ } \\
\text { rs12440667 }\end{array}$ \\
\hline & $\begin{array}{l}\text { rs3825942 } \\
(G>A)^{a}\end{array}$ & Chr15:73927241 & Missense & c. $458 \mathrm{G}>\mathrm{A}$ & p.G153D & 0.13 & АCCTCCGTCTCCCAGCAAC & TAGTTCTCGTACTGGCTGAC & 143 & $\begin{array}{c}\text { rs1078967/rs8041642/ rs8042039/ } \\
\text { rs8041685 }\end{array}$ \\
\hline & $\begin{array}{l}r s 2304721 \\
(C>A)^{a}\end{array}$ & Chr15:73948013 & Intron & $\begin{array}{l}\text { c. } 1602 \\
+111 C>A\end{array}$ & - & 0.23 & TGTTCATGTCCAATGTCCCC & CTGAGACCTAAATCTTCGGC & 140 & rs1440101/rs12594472/rs16958494 \\
\hline & $\begin{array}{l}r s 12441130 \\
(T>C)^{a}\end{array}$ & Chr15:73942561 & Nonsense & $\begin{array}{l}\text { C.1103- } \\
293 T>C\end{array}$ & p.T446R & 0.29 & AGCTTACATCTCGAGCTCTG & TTCATGCTGTTITCCCTGCC & 143 & rs2028386/rs4337252 \\
\hline \multirow[t]{10}{*}{$\begin{array}{l}\text { LOXL2 } \\
\text { (NM_002318) }\end{array}$} & $\begin{array}{l}\text { rs2294128 } \\
(C>T)^{\mathrm{a}}\end{array}$ & Chr8:23333413 & Synonymous & c.954C>T & p.A318A & 0.14 & TGCCAAGTGGCCACACCTC & CATGAAGAATGTCACCTGCG & 146 & $\begin{array}{c}\text { rs2294127/rs2294126/rs2294129/ } \\
\text { rs3779895/rs9792317/rs10503724/ } \\
\text { rs11775841/rs11987443/rs17089043/ } \\
\text { rs17089055 }\end{array}$ \\
\hline & $\begin{array}{l}r s 7818494 \\
(A>G)^{a}\end{array}$ & Chr8:23366501 & Intron & $\begin{array}{l}0.355 \\
+1496 \mathrm{~A}>\mathrm{G}\end{array}$ & - & 0.22 & GTTGGAAGGGAGGATAACAG & AGAATAGCGCAGACCTCAAC & 140 & $\begin{array}{c}\text { rs4872112/rs7835142/rs10096530/ } \\
\text { rs10099318/rs10112621/rs11135728/ } \\
\text { rs11992138/rs12674548/rs12677717/ } \\
\text { rs17089161 }\end{array}$ \\
\hline & $\begin{array}{l}r s 4323477 \\
(A>G)^{a}\end{array}$ & Chr8:23324229 & Intron & $\begin{array}{l}\text { C. } 1151- \\
1948 A>G\end{array}$ & - & 0.49 & ATAGACGTTCAGCCACAAGG & AGCCAACTTAAGAGCCTAGC & 126 & $\begin{array}{c}\text { rs7829632/rs11135726/rs12676713/ } \\
\text { rs13248926/rs13259317/rs13272473/ } \\
\text { rs13282766/rs17088178 }\end{array}$ \\
\hline & $\begin{array}{l}\mathrm{rs} 7818416 \\
(\mathrm{G}>A)^{\mathrm{a}}\end{array}$ & Chr8:23373510 & Intron & $\begin{array}{l}\text { C.-83- } \\
5076 \mathrm{G}>\mathrm{A}\end{array}$ & - & 0.43 & CAAGAGATCCTCCTACTCAG & ACCTTTGGCAATTCATTGGC & 148 & $\begin{array}{l}\text { rs7009281//rs11782783/rs4285498/ } \\
\text { rs6983061/rs13252670/rs13254155 }\end{array}$ \\
\hline & $\begin{array}{l}r s 1063582 \\
(G>T)^{a}\end{array}$ & Chr8:23309840 & Missense & c. $1708 \mathrm{G}>\mathrm{T}$ & p.M570L & 0.27 & TCTCTTGCCTTGTTGACCAG & AGTTCTCCTCCATGGCACAC & 136 & $\begin{array}{c}\text { rs3765215/rs3808521/rs4273857/ } \\
\text { rs4278162/rs4872103 }\end{array}$ \\
\hline & $\begin{array}{l}\text { rs2280936 } \\
(C>G)^{a}\end{array}$ & Chr8:23297824 & 3'UTR & c. $219 C>G$ & - & 0.11 & AGCAGCTCTGTGGACAAACC & CTACAGCTGTGTCTAAGCTC & 119 & rs1051157/rs7813349/rs7834641 \\
\hline & $\begin{array}{l}r s 2294133 \\
(C>T)^{a}\end{array}$ & Chr8:23368232 & Synonymous & c. $120 \mathrm{C}>\mathrm{T}$ & p.P40P & 0.23 & CATTACCCCGAGTACTTCCA & CATCATAGTACACCTCCACC & 139 & rs17089187/rs4871870/rs6557667 \\
\hline & $\begin{array}{l}\text { rs2280935 } \\
(A>C)^{a}\end{array}$ & Chr8:23297617 & 3'UTR & c. $426 \mathrm{~A}>\mathrm{C}$ & - & 0.37 & GGAGGGTTCATTGGAAGAG & TGACACGTGGACAAATGCGG & 127 & rs2280937/rs11990784 \\
\hline & $\begin{array}{l}\text { rs1010156 } \\
(\mathrm{T}>\mathrm{C})^{\mathrm{ab}}\end{array}$ & Chr8:23333428 & Synonymous & c.939T>C & p.S313S & 0.45 & CATGAAGAATGTCACCTGCG & GTCCTCACCTCTGGCTTGTA & 120 & - \\
\hline & $\begin{array}{l}r s 142252012 \\
(G>A)^{b}\end{array}$ & Chr8:23368219 & Missense & c. $133 \mathrm{G}>\mathrm{A}$ & p.H45Y & 0.01 & CATCATAGTACACCTCCACC & ATTACCCCGAGTACTTCCAG & 138 & - \\
\hline
\end{tabular}




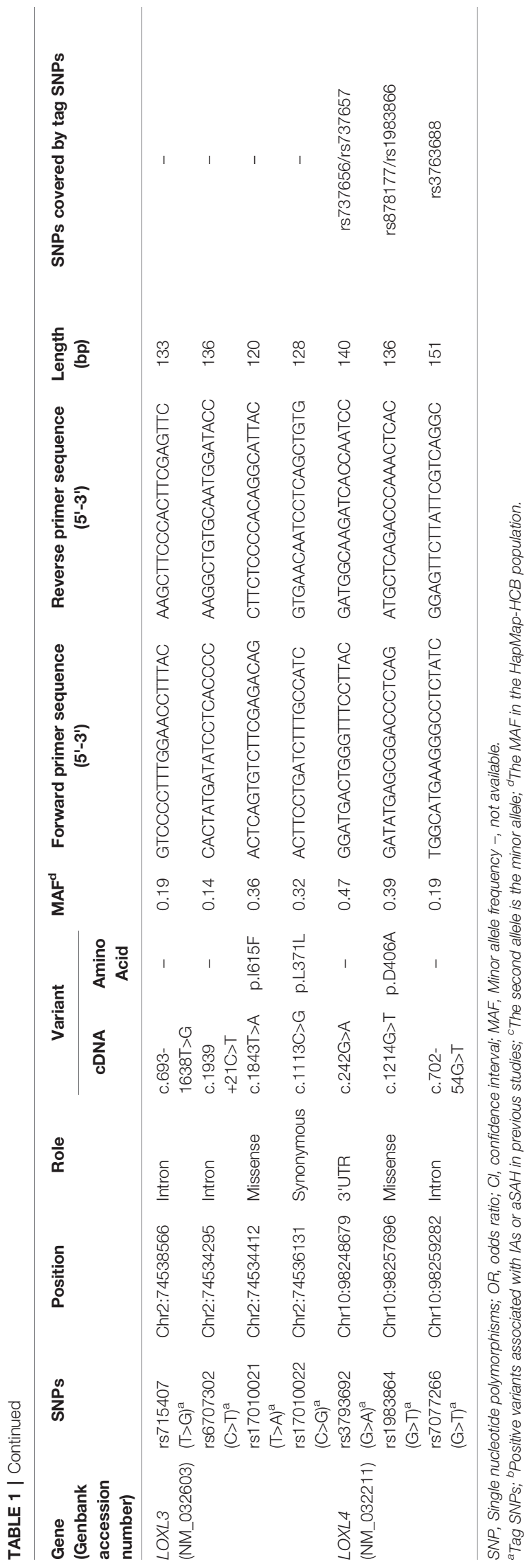

Polymerase chain reactions (PCR) were performed as described (17) in $5 \mu \mathrm{L}$ reaction mixtures containing $1.0 \mu \mathrm{L}$ template DNA (20-50 ng), PCR Primer mix ( $1 \mu \mathrm{L}), 10 \times$ PCR buffer $(0.5 \mu \mathrm{L})$, dddH2O $(1.8 \mu \mathrm{L}), 25 \mathrm{mM} \mathrm{MgCl} 2(0.4 \mu \mathrm{L}), 25 \mathrm{mM}$ dNTP $(0.1 \mu \mathrm{L})$, and $0.2 \mu \mathrm{L}$ Taq polymerase $(5 \mathrm{U} / \mu \mathrm{L})\left(\operatorname{HotStarTaq}^{\circledR}\right.$; Qiagen GmbH, Hilden, Germany). The amplification cycles were as follows: pre-denaturation for $2 \mathrm{~min}$ at $95^{\circ} \mathrm{C}$, followed by 45 cycles of $30 \mathrm{sec}$ at $9^{\circ} \mathrm{C}, 30 \mathrm{sec}$ at $56^{\circ} \mathrm{C}, 60 \mathrm{sec}$ at $72^{\circ} \mathrm{C}$, and a final elongation step of $5 \mathrm{~min}$ at $72^{\circ} \mathrm{C}$. The amplified products were stored at $25^{\circ} \mathrm{C}$. When the PCR endpoint was reached, excess dNTPs were removed using shrimp alkaline phosphatase followed by single nucleotide extension and resin desalination steps. We identified SNP genotypes and alleles using MALDITOF-MS, mass spectrum peaks and MassArray TYPER 4.0 software. Finally, target genotypes were interpreted according to the peaks.

\section{Statistical Analysis}

Data were analyzed using SPSS 23.0 (IBM Corp., Armonk, NY, USA). Continuous variables are described as means \pm standard deviation (SD) and categorical variables are expressed as ratios (\%). Pairs of normally distributed continuous variables were compared using Student t-tests, and distribution differences between two categorical variables were compared using chisquare or Fisher exact tests. The Hardy-Weinberg equilibrium of each SNP in the control group was assessed using chi-square tests. Pairwise LD was evaluated using the mean value of the squared correlation coefficient $\left(\mathrm{r}^{2}\right)$ and the standardized disequilibrium coefficient (D') in Haploview v.4.2 (https:// www.broadinstitute.org/haploview/haploview) (27). A pair of SNPs was determined in strong LD under the criterion $\mathrm{r}^{2} \geq$ $80 \%$. Complete $\mathrm{LD}$ was determined when $\mathrm{D}^{\prime}=1$ (28). We calculated OR and 95\% CI using binary logistic regression in different genetic models after adjusting for known risk factors (dominant, recessive, and additive models). The threshold of significance was set at $\mathrm{p}<0.05$. Statistical power (SP) was calculated according to the used significance level, sample size, obtained OR and the corresponding genotype carrier rate in the control group under two-sided Z test by using PASS 11 software (NCSS LLC, Kaysville, Utah, USA).

\section{RESULTS}

\section{Characteristics of Study Population}

Females comprised $69.5 \%$ of the 384 patients with IA and the 384 controls and $\sim 50 \%$ participants of both groups had hypertension $(P>0.05)$. Among the patients, $48.7 \%$ had IA located in the internal carotid arteries and $64.5 \%$ and $35.5 \%$ had single and multiple IA, respectively. The distribution of gender and hypertension did not differ significantly between patients with single or multiple IA and the controls. The mean age was lower and smoking, diabetes, and hyperlipidemia were less frequent in the patients than in the controls $(P<0.05)$. In single or multiple IA groups, approximately $50 \%$ and $20 \%$ of aneurysms were located in the internal carotid and middle cerebral arteries, 
respectively. Table 2 lists the detailed characteristics of the participants.

\section{Hardy-Weinberg Equilibrium and Linkage Disequilibrium Analysis}

The detection rate of all SNP genotypes was 100\%. Except for the allele frequency and genotype distribution of LOXL2 rs2280935, all SNPs in the controls were distributed in Hardy-Weinberg equilibrium $(P>0.05$; Table 3$)$. Figure 1 shows the linkage disequilibrium (LD) block of the targeted SNPs of the LOX family genes in all participants.

\section{Associations Between LOX Family Genes Polymorphisms and IA Susceptibility}

Table 3 lists the genotypes of 27 SNP of LOX family genes and their associations with IA. The results of univariate logistic regression analyses associated LOX rs10519694, LOXL1 rs3825942, and LOXL3 rs715407 polymorphisms with risk of total IA (Table S1). However, only the association of $L O X$ rs10519694 and IA remained significant after adjusting for age, smoking status, diabetes mellitus, and hyperlipidemia (recessive and additive models: OR, 3.88; 95\%CI, 1.12-13.47; $p=0.033$; and OR, 1.56; 95\%CI, 1.05-2.34; $p=0.030$, respectively; Table 3 ). The calculated statistical power of the association of LOX rs 10519694 and risk of IA under recessive and additive model was $100 \%$ and $41 \%$, respectively. The association was verified when used the 208 Chinese Han populations in the 1000 Genome Project as additional controls under additive model (OR, 1.89; 95\%CI, 1.24-2.89; $p=0.003$ ) (Table S2).

\section{Stratification Analysis}

Considering that single IA and multiple IA might be formed via different mechanisms, we stratified the patients according to the number of IA to assess associations between variants of $L O X$ family genes and risk of single or multiple IA. Only the LOX gene polymorphism was associated with the risk of single IA after adjusting for age, smoking status, diabetes mellitus, and hyperlipidemia. The SNP of LOX rs10519694 was associated with an increased risk of single IA (recessive and additive models: OR, 3.95; 95\%CI, 1.04-15.11, P = 0.044; SP, 100\% and OR, 1.64; 95\%CI, 1.04-2.56, P = 0.032, SP, 42\%, respectively, Table 4). The association was verified when used the 208 additional population control under additive model (OR, 1.97; 95\%CI, 1.26-3.09, $\mathrm{P}=0.003$ ) (Table S3). Another SNP of LOX rs2303656 was found to be associated with a decreased risk of single IA (dominant and additive models: OR, 0.44; 95\%CI, 0.19-0.96; $\mathrm{P}$ $=0.041$ and $\mathrm{OR}, 0.44,95 \% \mathrm{CI}, 0.20-0.96 ; \mathrm{P}=0.04$, respectively, Table 4). However, the statistical power was relatively low (60\%) and the association was not verified in the additional population control. Another gene polymorphism LOXL2 rs1010156 SNP was found to be positively associated with risk of multiple IA in the dominant model after adjusting for potential confounders (OR, 1.92; 95\% CI, 1.02-3.62, P = 0.044; Table 5) and the SP was $90 \%$ although the association was not replicated in the additional control (Table S4).

\section{DISCUSSION}

We aimed to determine associations between polymorphisms of LOX family genes and risk of IA in a Chinese population. We found that the LOX rs10519694 and LOXL2 rs1010156 polymorphism was associated with the risk of single and multiple IA respectively. As far as we can ascertain, this is the first systematic exploration of associations between $L O X$ family genes polymorphisms and the risk of IA in a Chinese population, and the findings offer a new perspective for the prevention and treatment of IA.

The LOX family genes comprise five members which encode LOX and LOX-like isoenzymes (LOXL1, LOXL2, LOXL3, and LOXL4), which are copper-dependent oxidases with a conserved C-terminal region that corresponds to the catalytic domain and a different N-termini (29). Therefore, each isoform has similar amine oxidase activities in which the $\epsilon$-amino group of peptidyl

TABLE 2 | Characteristics of the study population.

Characteristics
IA

Control $(n=384)$

\begin{tabular}{|c|c|c|c|c|}
\hline & & \\
\hline & Single IA ( $n=248)$ & Multiple IA ( $n=136)$ & Total $(n=384)$ & \\
\hline Age, years (Mean $\pm S D)$ & $57.3 \pm 10.4$ & $56.7 \pm 10.9$ & $57.1 \pm 10.6$ & $66.5 \pm 2.1$ \\
\hline Female, n (\%) & $166(66.9)$ & $101(74.3)$ & $267(69.5)$ & $267(69.5)$ \\
\hline Smoking, n (\%) & $30(12.1)$ & $15(11.0)$ & $59(15.4)$ & $111(28.9)$ \\
\hline Alcohol use, n (\%) & 24(9.7) & $12(8.8)$ & $36(9.4)$ & $48(12.5)$ \\
\hline Hypertension, n (\%) & $127(51.2)$ & $81(59.5)$ & $208(54.2)$ & $200(52.1)$ \\
\hline Diabetes mellitus, n (\%) & $15(6.0)$ & $9(6.6)$ & $24(6.3)$ & 65 (16.9) \\
\hline Hyperlipidemia, n (\%) & $13(5.2)$ & $9(6.6)$ & $22(5.7)$ & $8(2.1)$ \\
\hline \multicolumn{5}{|l|}{ Site of intracranial aneurysm, n (\%) } \\
\hline Internal carotid artery & $113(45.6)$ & $174(51.0)$ & $287(48.7)$ & - \\
\hline Middle cerebral artery & $45(18.1)$ & $69(20.2)$ & $114(19.4)$ & - \\
\hline Anterior cerebral artery & $15(6.0)$ & $24(7.0)$ & $39(6.6)$ & - \\
\hline Posterior cerebral artery & $2(0.8)$ & $13(3.8)$ & $15(2.5)$ & - \\
\hline Anterior communicating artery & $41(16.5)$ & $20(5.9)$ & $61(10.4)$ & - \\
\hline Posterior communicating artery & $18(7.3)$ & $16(4.7)$ & $34(5.8)$ & - \\
\hline BasilarNertebral artery & $14(5.6)$ & $25(7.3)$ & $39(5.1)$ & - \\
\hline
\end{tabular}

$S D$, standard deviation; Bold font indicates $p<0.05$ compared with control group -, not available. 
TABLE 3 | Multivariate logistic regression analysis of association of polymorphisms in LOX family genes and risk of IA in Chinese population.

\begin{tabular}{|c|c|c|c|c|c|c|c|c|c|c|}
\hline \multirow[t]{2}{*}{ Gene } & \multirow[t]{2}{*}{ SNP } & \multicolumn{2}{|c|}{ Genotype $^{a}$} & \multirow[b]{2}{*}{$P_{H W E}{ }^{b}$} & \multicolumn{2}{|c|}{ Dominant model } & \multicolumn{2}{|c|}{ Recessive model } & \multicolumn{2}{|c|}{ Additive model } \\
\hline & & Case (n) & Control (n) & & OR (95\%Cl) & $P$ value & OR $(95 \% \mathrm{Cl})$ & $P$ value & OR $(95 \% \mathrm{Cl})$ & $P$ value \\
\hline \multirow[t]{6}{*}{ LOX } & rs1800449(C>T) & 237/125/22 & $247 / 124 / 13$ & 0.867 & 1.15(0.80-1.65) & 0.450 & 1.52(0.65-3.56) & 0.336 & $1.16(0.86-1.58)$ & 0.328 \\
\hline & rs2956540(G>C) & $195 / 147 / 42$ & $210 / 146 / 28$ & 0.931 & $1.28(0.90-1.83)$ & 0.164 & $1.34(0.71-2.51)$ & 0.365 & $1.23(0.93-1.61)$ & 0.142 \\
\hline & rs10519694(C>T) & $313 / 50 / 21$ & $336 / 44 / 4$ & 0.194 & $1.54(0.94-2.51)$ & 0.084 & $3.88(1.12-13.47)$ & 0.033 & $1.56(1.05-2.34)$ & 0.030 \\
\hline & rs2303656(G>T) & $348 / 36 / 0$ & $342 / 41 / 1$ & 0.981 & $0.72(0.40-1.30)$ & 0.274 & - & - & $0.71(0.39-1.28)$ & 0.250 \\
\hline & rs763497(A>G) & 273/97/14 & 270/100/14 & 0.472 & $1.06(0.72-1.57)$ & 0.753 & 0.95(0.39-2.34) & 0.913 & $1.04(0.75-1.43)$ & 0.824 \\
\hline & rs3900446(A>G) & $305 / 72 / 7$ & $313 / 66 / 5$ & 0.778 & $1.01(0.65-1.58)$ & 0.954 & 2.37(0.63-8.90) & 0.200 & $1.09(0.74-1.61)$ & 0.673 \\
\hline \multirow[t]{4}{*}{ LOXL1 } & rs2165241(C>T) & $303 / 76 / 5$ & $313 / 66 / 5$ & 0.780 & 1.06(0.68-1.65) & 0.786 & $1.09(0.26-4.50)$ & 0.909 & $1.06(0.71-1.57)$ & 0.784 \\
\hline & rs3825942(G>A) & 284/90/10 & $304 / 78 / 2$ & 0.450 & $1.17(0.77-1.79)$ & 0.458 & $1.85(0.30-11.28)$ & 0.504 & $1.18(0.80-1.75)$ & 0.398 \\
\hline & rs2304721(C>A) & 223/133/28 & 208/147/29 & 0.910 & $1.11(0.77-1.58)$ & 0.571 & $0.92(0.47-1.77)$ & 0.792 & 1.05(0.80-1.38) & 0.739 \\
\hline & rs12441130(T>C) & $180 / 154 / 50$ & $149 / 178 / 57$ & 0.950 & $0.79(0.56-1.13)$ & 0.202 & $0.94(0.57-1.54)$ & 0.818 & $0.91(0.71-1.16)$ & 0.907 \\
\hline \multirow[t]{10}{*}{ LOXL2 } & rs2294128(C>T) & 298/80/6 & 279/95/10 & 0.856 & $0.77(0.51-1.16)$ & 0.209 & $0.62(0.17-2.26)$ & 0.472 & $0.78(0.54-1.13)$ & 0.186 \\
\hline & rs7818494(A>G) & 241/121/22 & 236/129/19 & 0.969 & $0.97(0.68-1.40)$ & 0.887 & $0.83(0.38-1.80)$ & 0.632 & $0.96(0.71-1.28)$ & 0.765 \\
\hline & rs4323477(A>G) & 97/197/90 & 87/188/109 & 0.942 & 1.08(0.71-1.62) & 0.731 & $0.67(0.45-1.01)$ & 0.056 & 0.88(0.69-1.13) & 0.327 \\
\hline & rs7818416(G>A) & 119/190/75 & $122 / 178 / 84$ & 0.458 & 0.92(0.63-1.33) & 0.644 & $0.84(0.54-1.30)$ & 0.428 & $0.91(0.72-1.16)$ & 0.458 \\
\hline & rs1063582(G>T) & 236/126/22 & 226/134/24 & 0.790 & $1.02(0.71-1.46)$ & 0.922 & $1.08(0.51-2.29)$ & 0.840 & $1.02(0.77-1.37)$ & 0.875 \\
\hline & rs2280936(C>G) & 241/125/18 & $245 / 124 / 15$ & 0.990 & $0.98(0.68-1.41)$ & 0.920 & $1.41(0.61-3.22)$ & 0.420 & 1.03(0.76-1.39) & 0.837 \\
\hline & rs2294133(C>T) & 236/116/32 & $215 / 147 / 22$ & 0.892 & $0.82(0.57-1.17)$ & 0.276 & 1.39(0.69-2.78) & 0.352 & $0.93(0.70-1.24)$ & 0.627 \\
\hline & rs2280935(A>C) & 155/177/52 & $128 / 212 / 44$ & 0.007 & $0.77(0.53-1.10)$ & 0.144 & $1.56(0.92-2.66)$ & 0.102 & $0.96(0.74-1.26)$ & 0.787 \\
\hline & rs1010156(T>C) & $103 / 197 / 84$ & $114 / 198 / 72$ & 0.693 & $1.18(0.80-1.75)$ & 0.401 & 1.07(0.69-1.66) & 0.777 & $1.10(0.85-1.42)$ & 0.473 \\
\hline & rs142252012(G>A) & $373 / 11 / 0$ & $372 / 12 / 0$ & 0.953 & 1.05(0.36-3.05) & 0.927 & - & - & 1.05(0.36-3.05) & 0.927 \\
\hline \multirow[t]{4}{*}{ LOXL3 } & rs715407(T>G) & 252/121/11 & $278 / 98 / 8$ & 0.983 & $1.29(0.89-1.89)$ & 0.183 & 0.95(0.29-3.06) & 0.931 & $1.22(0.87-1.72)$ & 0.246 \\
\hline & rs6707302(C>T) & 265/109/10 & 284/93/7 & 0.982 & $1.20(0.81-1.77)$ & 0.360 & $0.92(0.26-3.25)$ & 0.894 & $1.15(0.81-1.63)$ & 0.431 \\
\hline & rs17010021(T>A) & $166 / 176 / 42$ & 167/178/39 & 0.702 & $1.04(0.73-1.48)$ & 0.831 & $0.87(0.49-1.56)$ & 0.642 & 0.99(0.76-1.30) & 0.958 \\
\hline & rs17010022(C>G) & $174 / 167 / 43$ & $161 / 175 / 48$ & 0.999 & 0.99(0.69-1.42) & 0.982 & $0.83(0.48-1.45)$ & 0.516 & $0.96(0.74-1.24)$ & 0.742 \\
\hline \multirow[t]{3}{*}{ LOXL4 } & rs3793692(G>A) & 86/206/92 & 91/198/95 & 0.828 & $0.84(0.57-1.26)$ & 0.410 & $0.97(0.65-1.47)$ & 0.894 & 0.93(0.72-1.19) & 0.555 \\
\hline & rs1983864(G>T) & 126/192/66 & $124 / 183 / 77$ & 0.818 & $1.05(0.72-1.52)$ & 0.817 & $0.73(0.46-1.15)$ & 0.172 & 0.93(0.72-1.19) & 0.549 \\
\hline & rs7077266(G>T) & 271/104/9 & 273/97/14 & 0.358 & $1.02(0.70-1.50)$ & 0.911 & $0.81(0.31-2.16)$ & 0.682 & $0.99(0.72-1.37)$ & 0.964 \\
\hline
\end{tabular}

SNP, single nucleotide polymorphism; OR, odds ratio; Cl, confidence interval; -, not available.

${ }^{a}$ Genotype presented as wild type/heterozygous/homozygous; ${ }^{b}$ Hardy-Weinberg equilibrium test; Bold font indicates $p<0.05$.

lysine is oxidized to generate peptidyl aldehyde $(20,30,31)$. Collagen and elastin are the specific physiological substrates of LOX family oxidases. Cross-linked collagen and elastic fibers are essential for ECM stability and provide most of the tensile strength and structural integrity of connective tissue (32). The abnormal expression of LOX enzymes is related to changes in ECM composition characteristic of atherosclerosis and aortic aneurysms (21).

The LOX located at 5q23.1, which was the first identified subtype and represent of the $L O X$ family genes.LOX catalyzes the translation of peptidyl lysine and oxidizes it to peptidyl aldehyde and $\alpha$-aminohexyl- $\delta$ semialdehyde. The collagen and elastin crosslinking initiated by this chemical reaction assures deposition of these fiber proteins in the ECM (33). Changes in the ECM disrupt the vascular wall, as evidenced in atherosclerosis, a cardiovascular disease that features vigorous destruction of the ECM $(34,35)$. Some morphological changes caused by atherosclerosis can result in the deposition of fibrous tissues that ultimately develop into IA $(13,36)$. Thus, we hypothesis that the disrupted LOX expression might be associated with IA that is characterized by ECM destruction. The present study found that LOX rs10519694 was associated with the increased risk of single IA in recessive and additive models and the association was verified in the additional population control. Furthermore, similar to the findings of a case-control study by Hong et al., who associated the A allele of another polymorphism of $L O X$ (rs2303656) with decreased risk of IA $\left(P=8.2 \times 10^{-4}\right)$ in Korean population, we also identified that this variant was associated with the decreased risk of single IA in Chinese, even a definite conclusion couldn't be drawn considering the fact of that the statistical power was relatively low and the association was not replicated in the additional control. Hong et al. also found that the C allele of LOX rs3900446 and the $G$ allele of rs763497 with increased risk of IA (OR, 20.15; $P=4.8 \times 10^{-5}$ and $\mathrm{OR}, 2.26 ; P=4.8 \times 10^{-5}$ ) in Korean population, respectively (25). However, the polymorphisms of $L O X$ gene is not associated with IA in Japanese and Dutch (23), central European (22) and South Indian (24) populations. Lan Ma et al. found that another SNP of LOX (rs1800449) was associated with the susceptibility to coronary artery diseases in Chinese population (37) and a recent mouse model also suggested that the missense mutation ( $p . G 473 \mathrm{~A}$ ) caused by rs1800449 could lead to loss tumor suppressor function of the LOX propeptide and thus accelerate carcinogen-induced tumor formation (38). However, this SNP was not found to be associated with IA in our study. We speculate that these results are associated with the population genetic heterogeneity or limited statistical power of previous studies. These lines of evidence illustrated that the polymorphisms of LOX may perform roles in IA susceptibility in particular populations. The detail functions of the identified variants were not clear, considering the fact of that rs10519694 and rs2303656 are both 


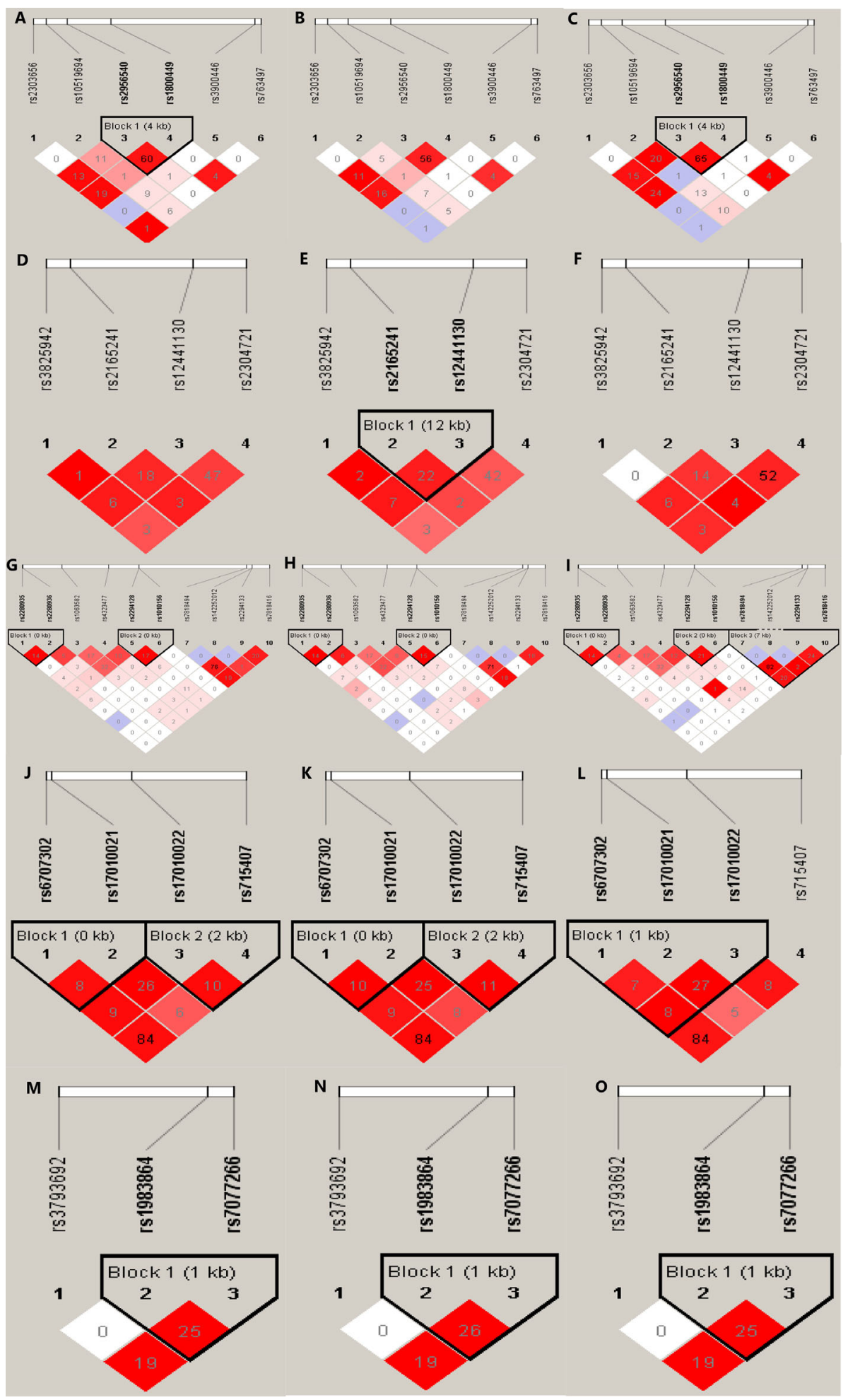

FIGURE 1 | Graphical representation of the SNP locations and LD structure of each isoform of LOX family genes. The SNP distribution and haplotype block structure across LOX family genes are shown. The measures of LD $\left(r^{2}\right)$ among all possible pairs of SNPs are shown graphically according to the shade of color, where white represents very low $r^{2}$ and scarlet represents very high $r^{2}$. The numbers in squares are $r^{2}$ values $\left(r^{2} \times 100\right)$. The graphics (A-C) represent the SNP locations and LD structures of LOX gene in total, IA and control group, respectively. Accordingly, graphics (D-F) were for LOXL1, graphics (G-I) were for LOXL2, graphics (J-L) were for LOXL3 and graphic (M-O) were for LOXL4, respectively. 
TABLE 4 | Multivariate logistic regression analysis of associations of polymorphisms in LOX family genes and risk of single IA in a Chinese population.

\begin{tabular}{|c|c|c|c|c|c|c|c|c|c|}
\hline \multirow[t]{2}{*}{ GENE } & \multirow[t]{2}{*}{ SNP } & \multicolumn{2}{|c|}{ Genotype $^{a}$} & \multicolumn{2}{|c|}{ Dominant model } & \multicolumn{2}{|c|}{ Recessive model } & \multicolumn{2}{|c|}{ Additive model } \\
\hline & & Case (n) & Control (n) & OR $(95 \% \mathrm{Cl})$ & $P$ value & OR $(95 \% \mathrm{Cl})$ & $P$ value & OR $(95 \% \mathrm{Cl})$ & $P$ value \\
\hline \multirow[t]{6}{*}{ LOX } & rs1800449(C>T) & $163 / 72 / 13$ & $247 / 124 / 13$ & $0.99(0.65-1.51)$ & 0.972 & $1.31(0.48-3.58)$ & 0.594 & $1.03(0.72-1.47)$ & 0.876 \\
\hline & rs2956540(G>C) & $137 / 87 / 24$ & $210 / 146 / 28$ & $1.11(0.74-1.67)$ & 0.615 & $1.21(0.58-2.51)$ & 0.617 & $1.10(0.80-1.51)$ & 0.546 \\
\hline & rs10519694(C>T) & 201/32/15 & $336 / 44 / 4$ & $1.64(0.95-2.83)$ & 0.078 & $3.95(1.04-15.11)$ & 0.044 & $1.64(1.04-2.56)$ & 0.032 \\
\hline & rs2303656(G>T) & 233/15/0 & $342 / 41 / 1$ & $0.44(0.19-0.96)$ & 0.041 & - & - & $0.44(0.20-0.96)$ & 0.040 \\
\hline & rs763497(A>G) & $177 / 64 / 7$ & 270/100/14 & $0.79(0.27-2.35)$ & 0.672 & $1.01(0.65-1.58)$ & 0.954 & 0.98(0.68-1.42) & 0.919 \\
\hline & rs3900446(A>G) & $203 / 40 / 5$ & $313 / 66 / 5$ & $0.86(0.51-1.44)$ & 0.560 & $3.64(0.92-14.34)$ & 0.065 & $1.01(0.64-1.59)$ & 0.969 \\
\hline \multirow[t]{4}{*}{ LOXL1 } & rs2165241(C>T) & $201 / 43 / 4$ & $313 / 66 / 5$ & $0.98(0.59-1.65)$ & 0.952 & 1.30(0.28-6.16) & 0.739 & $1.01(0.64-1.59)$ & 0.966 \\
\hline & rs3825942(G>A) & $186 / 56 / 6$ & $304 / 78 / 2$ & $1.07(0.66-1.73)$ & 0.792 & $2.29(0.32-16.38)$ & 0.410 & $1.11(0.71-1.73)$ & 0.656 \\
\hline & rs2304721(C>A) & $141 / 84 / 23$ & 208/147/29 & $1.18(0.79-1.78)$ & 0.420 & $1.18(0.58-2.41)$ & 0.652 & $1.14(0.83-1.55)$ & 0.420 \\
\hline & rs12441130(T>C) & $116 / 97 / 35$ & $156 / 171 / 57$ & $0.85(0.56-1.27)$ & 0.424 & $1.19(0.69-2.06)$ & 0.525 & $0.97(0.73-1.28)$ & 0.820 \\
\hline \multirow[t]{10}{*}{ LOXL2 } & rs2294128(C>T) & $198 / 54 / 4$ & 279/95/10 & $0.70(0.44-1.14)$ & 0.152 & $0.43(0.08-2.21)$ & 0.309 & $0.71(0.46-1.09)$ & 0.117 \\
\hline & rs7818494(A>G) & $158 / 74 / 16$ & 236/129/19 & $0.91(0.60-1.38)$ & 0.664 & 0.99(0.42-2.33) & 0.976 & $0.94(0.67-1.32)$ & 0.718 \\
\hline & rs4323477(A>G) & $60 / 129 / 59$ & 89/186/109 & $1.13(0.70-1.83)$ & 0.616 & $0.72(0.45-1.14)$ & 0.159 & $0.92(0.69-1.22)$ & 0.559 \\
\hline & rs7818416(G>A) & $92 / 110 / 46$ & $125 / 175 / 84$ & $0.89(0.58-1.36)$ & 0.586 & $0.72(0.43-1.21)$ & 0.216 & $0.86(0.65-1.14)$ & 0.297 \\
\hline & rs1063582(G>T) & $154 / 85 / 9$ & $226 / 134 / 24$ & $1.10(0.73-1.66)$ & 0.647 & $0.84(0.34-2.09)$ & 0.714 & $1.01(0.74-1.46)$ & 0.816 \\
\hline & rs2280936(C>G) & $153 / 85 / 10$ & $245 / 124 / 15$ & 1.03(0.68-1.56) & 0.880 & $1.11(0.39-3.13)$ & 0.848 & $1.04(0.73-1.48)$ & 0.846 \\
\hline & rs2294133(C>T) & $148 / 74 / 26$ & $215 / 147 / 22$ & $0.88(0.58-1.32)$ & 0.530 & 1.88(0.89-3.96) & 0.096 & $1.03(0.75-1.42)$ & 0.839 \\
\hline & rs2280935(A>C) & $101 / 111 / 36$ & $140 / 200 / 44$ & $0.88(0.58-1.33)$ & 0.531 & $1.58(0.86-2.91)$ & 0.141 & $1.04(0.76-1.42)$ & 0.795 \\
\hline & rs1010156(T>C) & $75 / 118 / 55$ & 114/198/72 & $0.94(0.60-1.46)$ & 0.780 & $0.95(0.57-1.60)$ & 0.855 & $0.96(0.72-1.28)$ & 0.772 \\
\hline & rs142252012(G>A) & 241/7/0 & $372 / 12 / 0$ & $1.20(0.34-4.27)$ & 0.780 & - & - & $1.20(0.34-4.27)$ & 0.780 \\
\hline \multirow[t]{4}{*}{$\angle O X L 3$} & rs715407(T>G) & $161 / 79 / 8$ & 278/98/8 & $1.22(0.79-1.90)$ & 0.366 & 1.18(0.32-4.36) & 0.800 & $1.19(0.81-1.75)$ & 0.381 \\
\hline & rs6707302(C>T) & $168 / 73 / 7$ & $284 / 93 / 7$ & $1.18(0.75-1.85)$ & 0.475 & $1.12(0.26-4.69)$ & 0.880 & $1.15(0.77-1.72)$ & 0.494 \\
\hline & rs17010021(T>A) & $112 / 111 / 25$ & 167/178/39 & $0.87(0.58-1.30)$ & 0.493 & $0.78(0.39-1.54)$ & 0.468 & $0.87(0.64-1.19)$ & 0.392 \\
\hline & rs17010022(C>G) & $110 / 112 / 26$ & $161 / 175 / 48$ & $0.11(0.74-1.68)$ & 0.609 & $0.85(0.45-1.61)$ & 0.614 & $1.02(0.75-1.38)$ & 0.892 \\
\hline \multirow[t]{3}{*}{ LOXL4 } & rs3793692(G>A) & $53 / 135 / 60$ & 94/195/95 & $0.98(0.61-1.57)$ & 0.930 & $0.99(0.62-1.59)$ & 0.962 & $0.99(0.84-1.32)$ & 0.933 \\
\hline & rs1983864(G>T) & 73/127/48 & $129 / 178 / 77$ & 1.06(0.69-1.63) & 0.791 & $0.77(0.45-1.31)$ & 0.334 & $0.95(0.71-1.26)$ & 0.717 \\
\hline & rs7077266(G>T) & $170 / 73 / 5$ & 273/97/14 & 1.02(.66-1.59) & 0.917 & $0.73(0.22-2.45)$ & 0.615 & $0.99(0.68-1.44)$ & 0.938 \\
\hline
\end{tabular}

SNP, single nucleotide polymorphism; OR, odds ratio; Cl, confidence interval; -, not available.

${ }^{a}$ Genotype presented as wild type/heterozygous/homozygous; Bold font indicates $p<0.05$.

intronic variants, as a tagSNP, the associations between them and IA might exist different possibilities: the polymorphism has a causal role or the polymorphism has no causal role but is associated with a nearby causal variant. The detailed mechanism of $L O X$ polymorphisms on IA should be further explored.

LOXL1-4 are located at 15q24.1, 8p21.3, 2p13.1, and 10q24.2, respectively. Similar with LOX, LOXL1 also contains an Nterminal propeptide, while the N-terminal of LOXL2-4 consists of four scavenger receptor cysteine-rich (SRCR) domains (29). The biological effects of LOXL1 are similar to those of LOX, and are significant not only for elastogenesis but also for supporting the deposition of elastin (39). For example, a large-scale GWAS study found that LOXL1 variants can increase the deposition of elastin and fibrillin-1 that stabilizes the ECM, thereby protecting against exfoliation syndrome (40). Since LOXL2 affects the pathophysiological processes of cancer, such as cell adhesion and invasion (30) and promotes endothelial tube formation by cross-linking collagen IV in the vascular system, its expression may be related to tumor angiogenesis and progression (21). The glycosylation and proteolytic processing of extracellular LOXL2 are essential for cross-linking basement membrane type IV collagen in the ECM $(41,42)$. A recent crystal structure study found that a point mutation of LOXL2 (N455Q) could affect the activity of the catalytic domain by eliminating the glycosylation in the fourth SRCR domains of LOXL2, and another mutation
(R257G) could prevent LOXL2 from proteolytic cleavage by serine protease, resulting in LOXL2 couldn't remove the first two SRCR domains and subsequently can't bind to type IV collagen, finally disturb the structural and functional stability of $\operatorname{ECM}(29,41)$. LOXL3 is expressed abundantly in the retina and central nervous system; abnormal LOXL3 expression is associated with cleft palate and spinal deformities (43). These anomalies may be associated with the inability of LOXL3 to effectively crosslink collagen (30). The LOXL4 is the latest discovery in the LOX family and limited information is available regarding this isoform. However, LOXL4 plays specific roles in the proliferation and metastasis of cells in certain malignancies, such as gastric and liver cancer $(44,45)$. Considering the role of LOXL4 in tumorigenesis, it may serve as a potential independent prognostic marker and therapeutic target for these cancers. Further detailed investigations are necessary to fully understand the biological functions of $L O X$ family gene members.

We found that one SNP of LOXL2 rs1010156 associated with the risk of multiple IA after adjusting for potential confounders (OR, 1.92; 95\% CI, 1.02-3.62, P = 0.044). Even the result was not verified in the additional control, we thought that the previous analysis was more reasonable due to that we just performed univariate logistic regression analysis in the additional controls and potential confounders were not adjusted due to these informations was not available. Our findings were similar to 
TABLE 5 | Univariate logistic regression analysis of association of polymorphisms in LOX family genes and risk of multiple IAs in a Chinese population.

\begin{tabular}{|c|c|c|c|c|c|c|c|c|c|}
\hline \multirow[t]{2}{*}{ GENE } & \multirow[t]{2}{*}{ SNP } & \multicolumn{2}{|c|}{ Genotype $^{a}$} & \multicolumn{2}{|c|}{ Dominant model } & \multicolumn{2}{|c|}{ Recessive model } & \multicolumn{2}{|c|}{ Additive model } \\
\hline & & Case (n) & Control (n) & OR $(95 \% \mathrm{Cl})$ & $P$ value & OR $(95 \% \mathrm{Cl})$ & $P$ value & OR $(95 \% \mathrm{Cl})$ & $P$ value \\
\hline \multirow[t]{6}{*}{$\angle O X$} & rs1800449(C>T) & $74 / 53 / 9$ & 247/124/13 & $1.41(0.84-2.38)$ & 0.198 & $1.77(0.58-5.38)$ & 0.316 & $1.37(0.89-2.11)$ & 0.150 \\
\hline & rs2956540(G>C) & $58 / 60 / 18$ & $210 / 206 / 46$ & $1.61(0.95-2.70)$ & 0.075 & 1.59(0.67-3.78) & 0.294 & 1.44(0.97-2.13) & 0.070 \\
\hline & rs10519694(C>T) & $112 / 18 / 6$ & $336 / 44 / 4$ & 1.48(0.71-3.09) & 0.297 & $4.28(0.76-24.08)$ & 0.099 & $1.52(0.82-2.80)$ & 0.184 \\
\hline & rs2303656(G>T) & $115 / 21 / 0$ & $342 / 41 / 1$ & - & - & $1.22(0.56-2.65)$ & 0.614 & $1.19(0.56-2.55)$ & 0.647 \\
\hline & rs763497(A>G) & $96 / 33 / 7$ & 270/100/14 & $1.23(0.3-4.17)$ & 0.741 & 1.13(0.65-1.98) & 0.669 & $1.12(0.71-1.76)$ & 0.638 \\
\hline & rs3900446(A>G) & $102 / 32 / 2$ & $313 / 66 / 5$ & $1.39(0.75-2.59)$ & 0.299 & 0.65(0.04-9.88) & 0.755 & $1.30(0.73-2.31)$ & 0.374 \\
\hline \multirow[t]{4}{*}{ LOXL1 } & rs2165241(C>T) & $102 / 33 / 1$ & $313 / 66 / 5$ & $1.12(0.60-2.10)$ & 0.722 & 0.66(0.07-6.3) & 0.711 & 1.06(0.61-1.86) & 0.834 \\
\hline & rs3825942(G>A) & $98 / 34 / 4$ & $304 / 78 / 2$ & $1.36(0.74-2.50)$ & 0.315 & $1.11(0.11-10.41)$ & 0.931 & $1.31(0.75-2.29)$ & 0.349 \\
\hline & rs2304721(C>A) & $82 / 49 / 5$ & 208/147/29 & $1.10(0.65-1.85)$ & 0.730 & $0.52(0.14-1.88)$ & 0.315 & 0.97(0.64-1.49) & 0.904 \\
\hline & rs12441130(T>C) & $64 / 57 / 15$ & $156 / 171 / 57$ & $0.84(0.50-1.42)$ & 0.512 & $0.62(0.28-1.39)$ & 0.250 & $0.82(0.56-1.19)$ & 0.297 \\
\hline \multirow[t]{10}{*}{ LOXL2 } & rs2294128(C>T) & $100 / 34 / 2$ & 279/95/10 & $0.97(0.54-1.76)$ & 0.922 & $1.10(0.20-5.96)$ & 0.909 & 0.99(0.59-1.66) & 0.959 \\
\hline & rs7818494(A>G) & $83 / 47 / 6$ & 236/129/19 & 1.08(0.64-1.92) & 0.786 & 0.66(1.19-2.33) & 0.519 & 0.99(0.64-1.54) & 0.984 \\
\hline & rs4323477(A>G) & $39 / 66 / 31$ & 89/186/109 & $0.92(0.51-1.67)$ & 0.793 & $0.92(0.51-1.67)$ & 0.793 & $0.56(0.30-1.06)$ & 0.075 \\
\hline & rs7818416(G>A) & $51 / 56 / 29$ & $125 / 175 / 84$ & $1.01(0.58-1.74)$ & 0.977 & $1.13(0.61-2.10)$ & 0.691 & $1.04(0.74-1.48)$ & 0.809 \\
\hline & rs1063582(G>T) & $82 / 41 / 13$ & $226 / 134 / 24$ & $0.90(0.52-1.53)$ & 0.684 & $1.80(0.65-5.04)$ & 0.260 & 1.02(0.66-1.58) & 0.928 \\
\hline & rs2280936(C>G) & 88/40/8 & $245 / 124 / 15$ & $0.85(0.49-1.45)$ & 0.542 & $2.04(0.72-5.83)$ & 0.182 & $1.00(0.65-1.55)$ & 1.000 \\
\hline & rs2294133(C>T) & $88 / 42 / 6$ & $215 / 147 / 22$ & $0.73(0.43-1.24)$ & 0.248 & $0.62(1.18-2.14)$ & 0.447 & $0.75(0.48-1.18)$ & 0.215 \\
\hline & rs2280935(A>C) & $63 / 57 / 16$ & $140 / 200 / 44$ & $0.62(0.37-1.05)$ & 0.077 & 1.47(0.68-3.18) & 0.324 & $0.84(0.56-1.26)$ & 0.398 \\
\hline & rs1010156(T>C) & 28/29/79 & 114/198/72 & $1.92(1.02-3.62)$ & 0.044 & $1.31(0.69-2.49)$ & 0.403 & $1.42(0.97-2.10)$ & 0.073 \\
\hline & rs142252012(G>A) & $132 / 4$ & $372 / 12 / 0$ & $0.94(0.21-4.12)$ & 0.932 & - & - & $0.94(0.21-4.12)$ & 0.932 \\
\hline \multirow[t]{4}{*}{ LOXL3 } & rs715407(T>G) & $91 / 42 / 3$ & $278 / 98 / 8$ & $1.46(0.84-2.55)$ & 0.177 & $0.64(0.09-4.42)$ & 0.649 & $1.32(0.80-2.16)$ & 0.277 \\
\hline & rs6707302(C>T) & $97 / 36 / 3$ & 284/93/7 & $1.29(0.73-2.27)$ & 0.376 & 0.68(0.09-4.92) & 0.702 & $1.20(0.72-1.99)$ & 0.489 \\
\hline & rs17010021(T>A) & $55 / 64 / 17$ & 167/178/39 & $1.35(0.79-2.30)$ & 0.269 & $1.12(0.49-2.53)$ & 0.794 & $1.21(0.82-1.79)$ & 0.339 \\
\hline & rs17010022(C>G) & $64 / 55 / 17$ & $161 / 175 / 48$ & $0.74(0.44-1.24)$ & 0.252 & 0.85(0.38-1.93) & 0.705 & $0.82(0.55-1.21)$ & 0.306 \\
\hline \multirow[t]{3}{*}{ LOXL4 } & rs3793692(G>A) & 36/68/32 & 94/195/95 & $0.76(0.44-1.34)$ & 0.347 & $0.99(0.54-1.85)$ & 0.990 & $0.90(0.62-1.29)$ & 0.550 \\
\hline & rs1983864(G>T) & $54 / 64 / 18$ & 129/178/77 & $0.93(0.54-1.59)$ & 0.777 & $0.71(0.35-1.43)$ & 0.331 & $0.87(0.61-1.26)$ & 0.471 \\
\hline & rs7077266(G>T) & $101 / 31 / 4$ & 273/97/14 & $0.88(0.49-1.55)$ & 0.647 & $1.10(0.30-3.98)$ & 0.887 & $0.92(0.57-1.48)$ & 0.742 \\
\hline
\end{tabular}

SNP, single nucleotide polymorphism; OR, odds ratio; Cl, confidence interval; -, not available.

${ }^{a}$ Genotype presented as wild type/heterozygous/homozygous; Bold font indicates $p<0.05$.

the results obtained by Akagawa et al. (18) who systematically screened LOXL family genes and reported that the LOXL2 polymorphism was associated with susceptibility to FIA. However, a comparison of SIA and FIA between patients and controls did not reveal any associations. In addition, using WES, $\mathrm{Wu}$ et al. found that a rare variant of LOXL2 c.133C > T (rs142252012) can increase susceptibility to FIA (26), however, we could not verify the association between this variant and susceptibility to IA in Chinese patients with SIA. We found an association between LOXL2 and multiple IA but not single IA, which may be attributed to the involvement of different pathophysiological pathways in the formation of multiple and single IA. Unlike single IA, multiple IA were not distributed randomly in the Circle of Willis, but were rather arranged in clusters near the index aneurysm, which may predict the formation of mirror aneurysms. Such aneurysmal clusters may be affected by genetic and hemodynamic variables (46). Multiple IA that develop more frequently in patients with familial IA can be larger and rupture at a higher frequency in younger individuals (14), which further suggests a genetic predisposition. This study did not find an association between LOXL1, LOXL3, and LOXL4 polymorphisms and susceptibility to IA, which was consistent with the results of Akagawa et al., who found no associations between LOXL1, LOXL3, and LOXL4 gene polymorphisms and IA susceptibility in a Japanese population (18). Considering the limited power of the statistics, larger sample size studies are needed in the future.

This study has several limitations. First, the controls comprised individuals who had not been diagnosed with IA or other cerebrovascular diseases. As some participants were assessed by imaging modalities, classification might have been biased. However, this influence was probably small considering that few people had IA in China. Second, we explored associations between polymorphisms in LOX family genes and risk of single and multiple IAs. Due to the sample size was relatively small and the statistical power was limited, the results may be not stable, further studies with larger sample size are needed to verify our findings. Third, considering the fact that the identified associated variants were tagSNP of target genes, we didn't know whether these variants were the real causal ones or just the surrogate of nearby causal variants, the potential functions and the detail pathological mechanisms of polymorphisms of $L O X$ family genes on IA are needed to further explored. Furthermore, this study has been performed in a central south Chinese population and the results may can't directly extrapolate to other ethnicities considering the fact that there may be population genetic heterogeneity. Our results need to be validated in further studies. Nevertheless, this study is the first to reveal associations between polymorphisms of the LOX family genes and susceptibility to IA in the Chinese population and offers a new perspective for the early diagnosis of IA. 


\section{CONCLUSIONS}

Our findings showed that $L O X$ and LOXL2 polymorphisms were associated with risk of single IA and multiple IA in a Chinese population, suggesting potential roles of these genes in IA. Further investigations are imperative to elucidate the effects of these genes on IA.

\section{DATA AVAILABILITY STATEMENT}

The original contributions presented in the study are included in the article/Supplementary Material. Further inquiries can be directed to the corresponding author.

\section{ETHICS STATEMENT}

The studies involving human participants were reviewed and approved by The Ethics Committee at Central South University (Permit No: CTXY-150002-1). The patients/participants provided their written informed consent to participate in this study.

\section{AUTHOR CONTRIBUTIONS}

Conceptualization: $\mathrm{CL}, \mathrm{CH}$, and JY. Data curation: CL, BL, and JL. Formal analysis: CL and BL. Funding acquisition: JY.

\section{REFERENCES}

1. Frösen J, Tulamo R, Paetau A, Laaksamo E, Korja M, Laakso A, et al. Saccular Intracranial Aneurysm: Pathology and Mechanisms. Acta Neuropathol (2012) 123(6):773-86. doi: 10.1007/s00401-011-0939-3

2. Vlak MH, Algra A, Brandenburg R, Rinkel GJ. Prevalence of Unruptured Intracranial Aneurysms, With Emphasis on Sex, Age, Comorbidity, Country, and Time Period: A Systematic Review and Meta-Analysis. Lancet Neurol (2011) 10(7):626-36. doi: 10.1016/S1474-4422(11)70109-0

3. Brinjikji W, Zhu YQ, Lanzino G, Cloft HJ, Kallmes D. Risk Factors for Growth of Intracranial Aneurysms: A Systematic Review and Meta-Analysis. AJNR Am J Neuroradiol (2016) 37(4):615-20. doi: 10.3174/ajnr.A4575

4. Jeon TY, Jeon P, Kim KH. Prevalence of Unruptured Intracranial Aneurysm on MR Angiography. Korean J Radiol (2011) 12(5):547-53. doi: 10.3348/kjr.2011.12.5.547

5. Li M-H, Chen S-W, Li Y-D, Chen Y-C, Cheng Y-S, Hu D-J, et al. Prevalence of Unruptured Cerebral Aneurysms in Chinese Adults Aged 35 to 75 Years: A Cross-Sectional Study. Ann Intern Med (2013) 159(8):514-21. doi: 10.7326/ 0003-4819-159-8-201310150-00004

6. Sonobe M. Small Unruptured Intracranial Aneurysm Verification Study: SUAVe Study, Japan. Stroke (2010) 41(9):1969-77. doi: 10.1161/STROKEAHA. 110.585059

7. Matsumoto K, Oshino S, Sasaki M, Tsuruzono K, Taketsuna S, Yoshimine T. Incidence of Growth and Rupture of Unruptured Intracranial Aneurysms Followed by Serial MRA. Acta Neurochir (Wien) (2013) 155(2):211-6. doi: 10.1007/s00701-012-1566-z

8. Suarez JI, Tarr RW, Selman WR. Aneurysmal Subarachnoid Hemorrhage. N Engl J Med (2006) 354(4):387-96. doi: 10.1056/NEJMra052732

9. Hackett ML, Anderson CS. Health Outcomes 1 Year After Subarachnoid Hemorrhage: An International Population-Based Study. Neurology (2000) 55 (5):658-62. doi: 10.1212/wnl.55.5.658
Investigation: $\mathrm{CL}, \mathrm{CH}, \mathrm{BL}, \mathrm{JL}, \mathrm{LH}, \mathrm{RD}, \mathrm{XL}, \mathrm{JZ}, \mathrm{LX}, \mathrm{SL}, \mathrm{YL}, \mathrm{DY}$, and WJ. Methodology: CH, CL, and JY. Project administration: CL, BL, and JY. Resources: CH, JL, WJ, and JY. Supervision: CL, $\mathrm{CH}$, and JY. Writing-original draft preparation: CL. Writingreview and editing: JY. All authors contributed to the article and approved the submitted version.

\section{FUNDING}

This work was supported by the National Nature Science Foundation, China [grant numbers: 81502881], and the Graduate Student Innovative Scientific Research Project of Central South University, China [grant numbers:1053320192459].

\section{ACKNOWLEDGMENTS}

The authors thank all participants in this study.

\section{SUPPLEMENTARY MATERIAL}

The Supplementary Material for this article can be found online at: https://www.frontiersin.org/articles/10.3389/fendo.2021. 642698/full\#supplementary-material

10. Riveroarias O, Gray A, Wolstenholme J. Burden of Disease and Costs of Aneurysmal Subarachnoid Haemorrhage (aSAH) in the United Kingdom. Cost Eff Resour Alloc (2010) 8:6. doi: 10.1186/1478-7547-8-6

11. Chalouhi N, Chitale R, Jabbour P, Tjoumakaris S, Dumont AS, Rosenwasser $\mathrm{R}$, et al. The Case for Family Screening for Intracranial Aneurysms. Neurosurg Focus (2011) 31(6):E8. doi: 10.3171/2011.9.FOCUS11210

12. Caranci F, Briganti F, Cirillo L, Leonardi M, Muto M. Epidemiology and Genetics of Intracranial Aneurysms. Eur J Radiol (2013) 82(10):1598-605. doi: 10.1016/j.ejrad.2012.12.026

13. Jung KH. New Pathophysiological Considerations on Cerebral Aneurysms. Neurointervention (2018) 13(2):73-83. doi: 10.5469/neuroint.2018.01011

14. Texakalidis P, Sweid A, Mouchtouris N, Peterson EC, Jabbour P. Aneurysm Formation, Growth and Rupture: The Biology and Physics of Cerebral Aneurysms. World Neurosurg (2019) 130:277-84. doi: 10.1016/j.wneu. 2019.07.093

15. Theodotou CB, Snelling BM, Sur S, Haussen DC, Peterson EC, Elhammady MS. Genetic Associations of Intracranial Aneurysm Formation and SubArachnoid Hemorrhage. Asian J Neurosurg (2017) 12(3):374-81. doi: 10.4103/1793-5482.180972

16. Yasuno K, Bakircioglu M, Low SK, Bilguvar K, Gaal E, Ruigrok YM, et al. Common Variant Near the Endothelin Receptor Type A (EDNRA) Gene Is Associated With Intracranial Aneurysm Risk. Proc Natl Acad Sci (2011) 108 (49):19707-12. doi: 10.1073/pnas.1117137108

17. Li B, Hu C, Liu J, Liao X, Yan J. Associations Among Genetic Variants and Intracranial Aneurysm in a Chinese Population. Yonsei Med J (2019) 60 (7):651-8. doi: 10.3349/ymj.2019.60.7.651

18. Akagawa H, Narita A, Yamada H. Systematic Screening of Lysyl Oxidase-Like (LOXL) Family Genes Demonstrates That LOXL2 Is a Susceptibility Gene to Intracranial Aneurysms. Hum Genet (2007) 121(3-4):377-87. doi: 10.1007/ s00439-007-0333-3 
19. Csiszar K. Lysyl Oxidases: A Novel Multifunctional Amine Oxidase Family. Prog Nuclc Acid Res Mol Biol (2001) 70:1-32. doi: 10.1016/s0079-6603(01) 70012-8

20. Molnar J, Fong KSK, He QP, Hayashi K, Csiszar K. Structural and Functional Diversity of Lysyl Oxidase and the LOX-Like Proteins. Biochim Biophys Acta (2003) 1647(1-2):220-4. doi: 10.1016/s1570-9639(03)00053-0

21. Martinez-Gonzalez J, Varona S, Canes L, Galan M, Briones AM, Cachofeiro V, et al. Emerging Roles of Lysyl Oxidases in the Cardiovascular System: New Concepts and Therapeutic Challenges. Biomolecules (2019) 9(10):610. doi: 10.3390/biom 9100610

22. Hofer A, Özkan S, Hermans M, Kubassek N, Sitzer M, Burtscher J, et al. Mutations in the Lysyl Oxidase Gene Not Associated With Intracranial Aneurysm in Central European Families. Cerebrovasc Dis (2004) 18(3):18993. doi: $10.1159 / 000079940$

23. Yoneyama T, Kasuya H, Onda H, Akagawa H, Jinnai N, Nakajima T, et al. Association of Positional and Functional Candidate Genes FGF1, FBN2, and LOX on 5q31 With Intracranial Aneurysm. J Hum Genet (2003) 48(6):309-14. doi: 10.1007/s10038-003-0030-6

24. Sathyan S, Koshy L, Lekshmi KRS, Easwer HV, Banerjee M. Lack of Association of Lysyl Oxidase (LOX) Gene Polymorphisms With Intracranial Aneurysm in a South Indian Population. Mol Biol Rep (2013) 40(10):5869-74. doi: 10.1007/s11033-013-2693-1

25. Hong EP, Pyeong JJ, Sung-Eun K, Yang JS, Jai CH, Kang SH, et al. A Novel Association Between Lysyl Oxidase Gene Polymorphism and Intracranial Aneurysm in Koreans. Yonsei Med J (2017) 58(5):1006-11. doi: 10.3349/ ymj.2017.58.5.1006

26. Wu YQ, Li Z, Shi Y, Chen L, Tan H, Wang Z, et al. Exome Sequencing Identifies LOXL2 Mutation as a Cause of Familial Intracranial Aneurysm. World Neurosurg (2017) 109:e812-e8. doi: 10.1016/j.wneu.2017.10.094

27. Barrett JC, Fry B, Maller J, Daly MJ. Haploview: Analysis and Visualization of LD and Haplotype Maps. Bioinformatics (2005) 21(2):263-5. doi: 10.1093/ bioinformatics/bth 457

28. Mueller JC. Linkage Disequilibrium for Different Scales and Applications. Brief Bioinform (2004) 4):355-64. doi: 10.1093/bib/5.4.355

29. Vallet SD, Ricard-Blum S. Lysyl Oxidases: From Enzyme Activity to Extracellular Matrix Cross-Links. Essays Biochem (2019) 63(3):349-64. doi: 10.1042/ebc20180050

30. Rodriguez-Pascual F, Rosell-Garcia T. Lysyl Oxidases: Functions and Disorders. J Glaucoma (2018) 27(p):S15-S9. doi: 10.1097/IJG. 0000000000000910

31. Grau-Bové X, Ruiz-Trillo IA, Rodriguez-Pascual F. Origin and Evolution of Lysyl Oxidases. Sci Rep (2015) 5:10568. doi: 10.1038/srep10568

32. Xiao Q, Ge G. Lysyl Oxidase, Extracellular Matrix Remodeling and Cancer Metastasis. Cancer Microenviron (2012) 5(3):261-73. doi: 10.1007/s12307012-0105-z

33. Lucero HA, Kagan HM. Lysyl Oxidase: An Oxidative Enzyme and Effector of Cell Function. Cell Mol Life Sci (2006) 63(19-20):2304-16. doi: 10.1007/ s00018-006-6149-9

34. Ruigrok YM, Rinkel GJE, Slot RVT, Wolfs M, Song T, Wijmenga, et al. Evidence in Favor of the Contribution of Genes Involved in the Maintenance of the Extracellular Matrix of the Arterial Wall to the Development of Intracranial Aneurysms. Hum Mol Genet (2006) 15(22):3361-8. doi: $10.1093 / \mathrm{hmg} / \mathrm{ddl} 412$

35. Cristina Rodríguez JM-G, Raposo B, Alcudia JF, Guadall A, Badimon L. Regulation of Lysyl Oxidase in Vascular Cells: Lysyl Oxidase as a New Player in Cardiovascular Diseases. Cardiovasc Res (2008) 79(1):7-13. doi: 10.1093/ $\mathrm{cvr} / \mathrm{cvn} 102$
36. Feng X, Qi P, Wang L, Lu J, Wang HF, Wang J, et al. Relationship Between Cerebrovascular Atherosclerotic Stenosis and Rupture Risk of Unruptured Intracranial Aneurysm: A Single-Center Retrospective Study. Clin Neurol Neurosurg (2019) 186:105543. doi: 10.1016/j.clineuro.2019.105543

37. Ma L, Song H, Zhang M, Zhang D. Lysyl Oxidase G473A Polymorphism Is Associated With Increased Risk of Coronary Artery Diseases. DNA Cell Biol (2011) 30(12):1033-7. doi: 10.1089/dna.2011.1261

38. de la Cueva A, Emmerling M, Lim SL, Yang S, Trackman PC, Sonenshein GE, et al. A Polymorphism in the Lysyl Oxidase Propeptide Domain Accelerates Carcinogen-Induced Cancer. Carcinogenesis (2018) 39(7):921-30. doi: 10.1093/carcin/bgy045

39. Liu X, Zhao Y, Gao J, Pawlyk B, Starcher B, Spencer JA, et al. Elastic Fiber Homeostasis Requires Lysyl Oxidase Like 1 Protein. Nat Genet (2004) 36 (2):178-82. doi: 10.1038/ng1297

40. Tin A, Mineo O, Mei CL, Ursula S-S, Gudmar T, Takanori M, et al. Genetic Association Study of Exfoliation Syndrome Identifies a Protective Rare Variant at LOXL1 and Five New Susceptibility Loci. Nat Genet (2017) 49 (7):993-1004. doi: 10.1038/ng.3875

41. Zhang X, Wang Q, Wu J, Wang J, Shi Y, Liu M. Crystal Structure of Human Lysyl Oxidase-Like 2 (hLOXL2) in a Precursor State. Proc Natl Acad Sci USA (2018) 115(15):3828-33. doi: 10.1073/pnas.1720859115

42. López-Jiménez AJ, Basak T, Vanacore RM. Proteolytic Processing of Lysyl Oxidase-Like-2 in the Extracellular Matrix Is Required for Crosslinking of Basement Membrane Collagen IV. J Biol Chem (2017) 292(41):16970-82. doi: 10.1074/jbc.M117.798603

43. Jian Z, Rui Y, Liu Z, Hou C, Wen Z, Zhang A, et al. Loss of Lysyl Oxidase-Like 3 Causes Cleft Palate and Spinal Deformity in Mice. Hum Mol Genet (2015) 21):6174-85. doi: 10.1093/hmg/ddv333

44. Li RK, Zhao WY, Fang F, Zhuang C, Zhang XX, Yang XM, et al. Lysyl Oxidase-Like 4 (LOXL4) Promotes Proliferation and Metastasis of Gastric Cancer Via FAK/Src Pathway. J Cancer Res Clin Oncol (2015) 141(2):269-81. doi: 10.1007/s00432-014-1823-z

45. Li R, Wang Y, Zhang X, Feng M, Ma J, Li J, et al. Exosome-Mediated Secretion of LOXL4 Promotes Hepatocellular Carcinoma Cell Invasion and Metastasis. Mol Cancer (2019) 18(1):18. doi: 10.1186/s12943-019-0948-8

46. Roethlisberger M, Achermann R, Bawarjan S, Stienen MN, Fung C, Dalonzo D, et al. Predictors of Occurrence and Anatomic Distribution of Multiple Aneurysms in Patients With Aneurysmal Subarachnoid Hemorrhage. World Neurosurg (2017) 111:e199-205. doi: 10.1016/j.wneu.2017.12.046

Conflict of Interest: The authors declare that the research was conducted in the absence of any commercial or financial relationships that could be construed as a potential conflict of interest.

Publisher's Note: All claims expressed in this article are solely those of the authors and do not necessarily represent those of their affiliated organizations, or those of the publisher, the editors and the reviewers. Any product that may be evaluated in this article, or claim that may be made by its manufacturer, is not guaranteed or endorsed by the publisher.

Copyright $\odot 2021 \mathrm{Luo}, \mathrm{Hu}, \mathrm{Li}, \mathrm{Liu}, \mathrm{Hu}$, Dong, Liao, Zhou, Xu, Liu, Li, Yuan, Jiang and Yan. This is an open-access article distributed under the terms of the Creative Commons Attribution License (CC BY). The use, distribution or reproduction in other forums is permitted, provided the original author(s) and the copyright owner(s) are credited and that the original publication in this journal is cited, in accordance with accepted academic practice. No use, distribution or reproduction is permitted which does not comply with these terms. 